\title{
Reform and Practice of "Spectral Imaging Technology and Its Application" Course for Professional Degree Postgraduates
}

\author{
You-wen TIAN, Tong-yu XU* \\ College of Information and Electric Engineering, \\ Shenyang Agricultral University, \\ Shenyang, China \\ youwen_tian10@163.com
}

\author{
Jun WANG, Ying-li CAO, Ping SONG \\ College of Information and Electric Engineering, \\ Shenyang Agricultral University, \\ Shenyang, China
}

\begin{abstract}
In order to meet the needs of training high-level applied talents, the course of Spectral Imaging Technology and its Application was taken as the research object in this paper, and the course reforming from four aspects: course content, teaching mode, teaching method and examination method was studied. Guided by the new engineering concept, the teaching content was integrated into the frontier hot spots such as big data and artificial intelligence. Guided by the new engineering concept, the teaching content was integrated into the frontier hot spots such as big data and artificial intelligence. Based on the "Internet +" curriculum resources sharing platform, the blended teaching mode was adopted, four teaching methods were combined organically, a multi-dimensional evaluation system was constructed. The teaching practice shows that the curriculum reform measures proposed in this paper effectively improve the autonomous learning ability and the ability of scientific research innovation and practical application of professional postgraduates.
\end{abstract}

Keywords-Curriculum Reform; Professional Degree Postgraduate; Spectral Imaging Technology and Its Application; new engineering; hybrid mode

\section{INTRODUCTION}

Professional degree postgraduate education is an important symbol of the development level of education and science and technology in a country, and it is also the industry foundation and important channel for the cultivation of high-level applied talents[1]. Postgraduate curriculum construction is closely related to the quality of students' training and is also an important part of professional master's construction. The professional degree of Master of Agriculture in the field of Agricultural Engineering and Information Technology is a professional degree related to the qualifications in this field which mainly cultivates applied, cross-cutting and compound high-level talents for enterprises, institutions and management departments in the fields of agricultural informatization, such as technology research, development, application, promotion and management, new rural development, modern agricultural education, etc. The graduate course of "Spectral Imaging Technology and Its Application" is a professional course for agricultural engineering and information technology. Some of its contents involve the requirements of new engineering such as big data, cloud computing, artificial intelligence, and intelligent manufacturing, and so on.

The current situation and problems were analyzed in the teaching of professional degree postgraduates in China in this study. The curriculum reform was taken as the starting point. The new engineering requirements were taken as guidance. The information technology was integrated with education and teaching under the background of "Internet + education". The course of "spectrum imaging technology and its application" was taken as an example, we had been building a platform for sharing curriculum network resources and carry out reforms and practices in curriculum contents, models, methods, and assessment so as to improve graduate students' innovative quality, scientific research literacy and practical ability, and cultivate more high-level innovative applied talents in line with the national strategy and the major needs of the industry. It is hoped that the research on the teaching reform of this course will lead to the construction of other courses.

\section{CURRENT TEACHING SituAtion OF PROFESSIONAL DEgREE POSTGRADUATE COURSES}

Since the beginning of full-time professional degree postgraduate enrollment in 2009, professional degree education has developed rapidly in the past ten years and achieved remarkable results, which has trained a large number of highlevel applied talents for national construction. The training orientation of professional degree postgraduates laid stress on practice, application and innovation. But at present, the training of professional master's degree postgraduates in China is still in the initial stage of exploration, and all aspects of talent training mode neglect the cultivation of innovative ability and comprehensive quality of postgraduates. Compared with Europe and the United States, Japan and Singapore, there are still a few successful experiences. There are slight deficiencies in the mode innovation, curriculum construction, professional competence and professional quality training of professional master's degree[2-3]. Especially, there are still some problems in the teaching of postgraduate courses, which mainly reflected in the following four aspects.

Research Topics of the Agricultural and Forestry Subject Working Committee of the Chinese Academy of Degree and Graduate Education; Research Project of Postgraduate Education and Teaching Reform in Shenyang Agricultural University. 
- Teaching resources are single. Most postgraduate courses were taught on the basis of textbooks. Some courses even lacked textbooks which knowledge was trivial and complicated. The case of "forgotten after learning" existed basically. Finally, it will fundamentally affect the effective formation of a solid professional foundation for postgraduates.

- Teaching model was still traditional, and students were not active in learning. At present, most of the teachers still gave priority to traditional classroom teaching, which was less integrated with practical projects, so that students' principal position has not been truly implemented. So that students' interest in learning was not high, their initiative was not strong, they were lazy in thinking in class, and the classroom atmosphere was not active enough. And the depth of academic discussions was not enough, which was not conducive to graduate students' the cultivation of innovative thinking and innovation and practical application ability.

- The teaching content was obsolete and slow to update, which laged far behind the actual application. In recent years, new scientific research achievements had been emerge in endlessly such as the hyperspectral imaging field. While the content of classroom teaching was mainly based on traditional theory, prospective and closely integrated with the front line of learning was scarce, and graduate students lacked practical project exercise, which made graduate students poor practical ability and not adapts to the requirements of new subjects.

- The traditional postgraduate course assessment usually took the final examination as the main means, and the evaluation of the learning process was less. From the content of the assessment, the distinction of the assessment between basic knowledge, innovative thinking, discovery problem and solving problem of graduate students were not high. Without scientific research methods and training of scientific research ability, graduate students' innovative inspiration and scientific thinking cannot be effectively stimulated. It is difficult to mobilize students' learning enthusiasm, and it is not conducive to the cultivation of students' innovative ability.

\section{REFORM AND PRACTICE OF GRADUATE COURSES WITH PROFESSIONAL DEGREES}

The advent of the "Internet +" era has accelerated the pace of education in the direction of informatization and modernization, and this trend is irresistible. With the further development of the new engineering, the requirement of Master of Agricultural Engineering and Information Technology is increasing. In order to meet the requirements of the new engineering era, the teaching and curriculum reform in postgraduate training must focus on the growth of postgraduates, take laying a good foundation for knowledge as the premise, and take the cultivation of innovation ability, independent thinking ability and critical thinking as the goal. Starting from the long-term development of postgraduates' knowledge needs and the cultivation of their innovative ability, the cultivation of professional postgraduates was explored through the implementation of postgraduate curriculum reform including content, mode, method and assessment in this study.

\section{A. Reforming the Teaching Content of the Course under the Guidance of the New Engineering Concept}

With the deepening of the reform of the curriculum system of higher education, the industry demand and ability requirement for graduate students majoring in agricultural engineering and information technology are also changing. With the emergence of new theories and methods, the content of the curriculum has undergone unprecedented changes in depth and breadth, and the scope of the curriculum is increasingly broad. The content is constantly expanding and updating, the amount of knowledge in the curriculum is significantly increasing, and the research frontier is changing with each passing day. Therefore, in order to better meet the training needs of students majoring in agricultural engineering and information technology, it is imperative to reform the content of the course "Spectral Imaging Technology and its Application", and it is of great significance to train professionals with social needs.

Master of Professional Degree in Agricultural Engineering and Information Technology trains students to have solid professional knowledge, innovative thinking and practical ability. The course of "Spectral Imaging Technology and Its Application" is a frontier academic seminar, a comprehensive course integrating theory learning, social cognition and student education, and a course focusing on ability system. Compared with the traditional classical courses, it is also a course with constantly changing contents and fast updating. Therefore, in the teaching of "Spectral Imaging Technology and Its Application" postgraduate course, the main basis for the selection of the course content was to attach importance to the theoretical system and consolidate the foundation, and to pay attention to the research hotspots of the subject and enrich the teaching content with the latest research trends. In the teaching reform, the choice of course content should reflect the accumulation of subject knowledge, and we fully considered the choice between traditional spectral imaging data processing methods and modern technology methods. And the traditional theories of image processing, spectral analysis, feature selection, pattern recognition were retained, such as median filtering, threshold segmentation, multiple scattering correction, partial Least Square, PCA, Linear Discrimination, Neural Network Recognition, etc. We also paid attention to keeping pace with the times and incorporates the latest achievements in discipline construction and scientific research into the curriculum content. According to the requirements of the new subject, this course integrated the contents of big data, cloud computing, artificial intelligence, intelligent manufacturing, robots, such as genetic algorithm, particle swarm optimization, support vector machine algorithm, etc. These algorithms were applied to apple quality detection based on spectral imaging, cherry defect detection and so on. At the same time, this course also combined the actual cases of agricultural production, so that the content of graduate courses has the characteristics of systematicness, innovation, research and practice. For example, 
detection of cucumber diseases based on image processing, identification of apple brown rot and water core diseases based on near infrared spectroscopy, chlorophyll detection of cucumber leaves based on hyperspectral image technology, physical damage detection of pear based on near infrared hyperspectral, and response of mountain grape to downy mildew infection based on chlorophyll fluorescence imaging variation analysis, analysis of water transfer in rice seed soaking process based on low field nuclear magnetic resonance and imaging technology, etc. In a word, through the reform of postgraduate curriculum content, it promotes the cultivation of postgraduate knowledge acquisition ability, independent research ability and ability to solve practical problems, and promotes the cultivation of high-quality innovative practical talents.

\section{B. Reforming Curriculum Teaching Mode Based on "Internet}

In the teaching of postgraduate courses, how to realize students' ability of independent thinking, problem solving and innovative practice is the basic goal. Postgraduate learning is based on basic theory learning and aims at developing students' innovative thinking and practical problem solving ability. Active and critical learning should be its basic characteristics. Based on the "Internet +", a resource sharing platform was constructed for postgraduate courses of spectrum imaging technology and its application, the teaching mode of the course was reformed, the form of blended teaching was adopted in this study. Compared with traditional teaching, hybrid teaching mode increased the part of teaching activities on the Internet platform, which combined the advantages of traditional teaching and online teaching. Through the organic combination of the two teaching organizational forms, graduate students' learning can be guided from theory to practice to innovative learning.

Relying on the resource sharing platform of "Spectral Imaging and its Application" course, a hybrid teaching mode combining online including autonomous Learning, collaborative learning, discussion and guidance and offline including lecture, report and discussion was developed to realize the flip classroom. The prominent features of this model are online resources, offline activities and process evaluation. Among them, online resources focused on knowledge presentation, explanation and assistant understanding, including teaching materials, teaching PPT, video and other shared resources. And online learning and guidance resources, scientific research case base, scientific and technological frontier and other parts were established. Combined with the actual cases of agricultural production, the latest achievements in discipline construction, scientific research were integrated into course network resources, as well as the requirements of new subjects such as big data, cloud computing, artificial intelligence, intelligent manufacturing, robotics and so on. Offline activities were focused on the examination and consolidation of online knowledge learning, breakthroughs in the discussion of difficult problems, and in-depth study of knowledge application problem solving. The process assessment focused on providing students with timely learning feedback, which was reflected in the comments, peer reviews, mutual evaluations and some small tests of teachers and peers. Offline mainly lies in teachers' timely comments and homework comments. The reform of the teaching mode of "Spectral Imaging Technology and Its Application" has adopted the online and offline hybrid teaching mode. Firstly, the content of the course was analyzed, which was divided into basic theoretical knowledge and practical case application. Their learning was completed online and offline respectively. "Off-line" is mainly to study and discuss practical cases. Each group, who divided before learning, with specific case practice tasks, prepared the contents and topics of classroom reports according to its own case themes and presents them in class. Before classroom presentations, teachers need to report to them. The content is audited, and the classroom demonstration can only be carried out after the examination, but the customs need to be further revised and improved. Before the group report, the teacher gave a brief introduction to the background of this practical case, and then the group members reported. Each group member reported for 15 minutes. After the report, the member throws the topic of discussion to the peers. The discussion time was 15 minutes. During the period, the teacher could guide the graduate students to participate in classroom discussions. And according to the actual teaching situation, the teacher could guide graduate students to think deeply about problems, timely problem extension and feedback.

\section{Reforming Teaching Methods}

Teaching is a "system engineering". To study the high efficiency of the system, the selection and application of teaching methods play a decisive role. We often preach that there is no definite way to teach, but there is a proper way to teach. There are many methods in teaching. Only by thorough understanding of the classroom deeply, timely regulation and flexible selection of appropriate methods, we can have good teaching results. Therefore, in teaching, there is no teaching method that can run through the whole class to complete the teaching task well, but the basic teaching methods are organically integrated and optimized for the application. In view of this, in the teaching practice of "Spectral Imaging Technology and Its Application", the four methods of problembased teaching, seminar-based teaching, case-based teaching and project-based teaching were organically combined to complete the teaching task throughout the course.

Students could study online resources of the course through the network teaching platform. In online learning and offline learning, teaching implemented active learning methods such as problem-based learning, discussion-based learning, casebased learning and project-based learning. Firstly, teachers set up academic background and put forward relevant problems according to the actual needs of agricultural production. Students searched for relevant information online through the network teaching platform, and explored solutions and methods to solve problems with the combination of big data, artificial intelligence and other new engineering content, initially formed their own views. Then, on-line students were divided into groups, who and teachers analyzed and discussed the problems together. Final solutions were obtained and implemented. After class, the related projects were arranged to students according to the actual needs for further development and research, which improved the postgraduates ability of raise, analyze, explore 
and solve problems, and cultivated their academic research ability and practical application ability. The hybrid teaching could also be carried out combined online and offline through cases. That is, a "case chain" was formed combining with agricultural production examples, according to the form of "problem-based case $\rightarrow$ analytical case $\rightarrow$ breakthrough case $\rightarrow$ expanding case" combining with agricultural production examples, using artificial intelligence method to guide students to explore the frontline problems of agricultural production, which stimulated students' interest in learning, opened up students' innovative thinking, enhanced students' engineering practice ability and comprehensive ability to solve problems. It will play a positive role in improving the quality of training high-quality innovative and applied talents and skilled personnel to combine flexibly several effective ways in the teaching process.

\section{Reforming Examination Methods}

Assessment is one of the important ways to check the teaching effect, evaluate the teaching quality and measure whether the teaching goal is achieved or not[6]. Timely feedback of learning effect is an important means to maintain learning motivation. A mixed teaching model was adopted in this study, which centered on students. And a multidimensional evaluation system was constructed combined online evaluation with offline assessment, and combined process evaluation with final assessment from the aspects of the main body, methods and means of assessment, which stimulated learning motivation and let students play the leading role in learning. The final score composition of students was online evaluation accounting for $30 \%$, offline assessment accounting for $20 \%$, stage test accounting for $20 \%$ and project assessment accounting for $30 \%$. On-line evaluation mainly checked the enthusiasm of students' self-learning and the utilization rate of shared resources based on the students' learning situation of "Spectral Imaging and Its Application" course resource sharing platform online, that is, learning progress, learning time, resource viewing, evaluation, online participation in discussion, etc. Off-line assessment mainly checked students' enthusiasm for classroom participation in teaching based on students' attendance, discussion, report, participation in classroom teaching activities. The stage test was mainly completed by the realization of the algorithm of each chapter arranged offline, which examined the students' mastery and application of each chapter. The project assessment mainly examined the students' ability of independent innovation and practical application according to the situation of communication and discussion, communication and expression, group cooperation, method application and end effect in the process of completing the project. The multidimensional evaluation system that the single result assessment in the past was replaced by the process assessment emphasized that the ultimate goal of the evaluation is to fully understand the students' learning process to stimulate students' learning and to improve teachers' teaching.

\section{CONCLUSION}

With the increasing demand for professional postgraduates, professional postgraduate education has become a hot topic in social research in recent years. This study holds that the training of professional postgraduates must attach importance to the construction of curriculum system and constantly optimize and adjust it. The balance between professional courses and elective courses, theoretical teaching and practical teaching, professional foundation of disciplines and professional ability training must be well handled. We must attach importance to the reform of curriculum content, which should keep up with the trend of the times and the frontier of the subject, in order to meet the rapid development of social needs. We must attach importance to the reform of teaching mode and introduce new technology, new ideas and new ways into the teaching mode so as to change and optimize the traditional classroom and make it play its best benefit. We must attach importance to the reform of teaching methods, follow the basic laws of teaching and learning, optimize and select various methods to play the greatest role and maximize the benefits of the classroom, so as to improve the autonomous learning ability and scientific research and innovation ability of professional postgraduates. Combined with the comprehensive evaluation of multi-faceted assessment, it provides a guarantee for a good classroom teaching model. It is hoped that this study will provide some references for the reform of professional master's curriculum in the future, and then improve the overall quality of professional master's education.

\section{ACKNOWLEDGMENT}

This research was financially supported by Research Topics of the Agricultural and Forestry Subject Working Committee of the Chinese Academy of Degree and Graduate Education and Research Project of Postgraduate Education and Teaching Reform in Shenyang Agricultural University.

\section{REFERENCES}

[1] Zhang Lei, Li Ting, Liu You-quan. "Reflection on The Education of Master Degree Students in Professional Degree under the New Situationin China, ” Education Teaching Forum, vol. 24, pp, 207-209, June, 2019. (in Chinese)

[2] Zhang Xiao-li, Yu Shi-ming. "Reflection and reform on the training model of professional master degree postgraduates in China, ” Academic Degrees \& Graduate Education, vol. 14, pp 55-59, October 2012. (in Chinese)

[3] Yang Zhen. “A Comparison of the Training Mode of Professional Degree for Graduates at Home and Abroad, ” Journal of Educational Science of Hunan Normal University, vol. 12, pp. 93-97, February 2013. (in Chinese)

[4] Li Hua, Shi Xia-rong, Zhang Liy-ong. "Professional Degree Education and Curriculum Reform of Modern Educational Technology," EEducation Research, vol 40, pp. 112-121, April 2019. (in Chinese)

[5] Guo Hong-guang, Wang Fei, LI Zhi-gang. "The Teaching Reform and Practice of Postgraduate Courses Based on"Internet +", ” Journal Of Shanxi institute of economic management, vol. 26, pp. 92-95, March 2018. (in Chinese)

[6] Li Feng, Guo Xiao-fang, Zhang Zhen-kai. "Research and practice of the Blending Teaching Model of Graduate Courses Based on the Massive Open Online Course, ” Meitan Higher Education, vol. 35, pp. 64-67, March 2017. (in Chinese) 